\title{
Application of a novel artificial intelligence system in guiding the targeted puncture of a pancreatic mass
}

Endoscopic ultrasound-guided fine-needle aspiration (EUS-FNA) is a first choice for acquiring samples from a pancreatic lesion [1]. However, due to the heterogeneity of the tumor, inaccurate localization of the positive puncture site will lead to a missed diagnosis The combination of contrast-enhanced harmonic endoscopic ultrasound and EUS-FNA can help to avoid puncture in necrotic areas, thus improving the diagnostic rate [2]. Unfortunately, the naked eye is not reliable for identifying and differentiating the targeted puncture sites suggested by contrast-enhanced harmonic EUS.

Therefore, we developed a novel system based on deep convolutional neural networks and random forest algorithms in order to identify and track the pancreatic masses dynamically in real time via describing time-intensity curve characteristics of each area of the pancreas, identifying points of interest, and guiding EUS-FNA.

A 55-year-old man was admitted to our department because of abdominal pain for 4 months. Computed tomography (CT) showed a lesion $8.3 \times 6.3 \mathrm{~cm}$ in the pancreatic body and tail (>Fig. 1). The patient decided to undergo EUS-FNA with the guidance of the novel system ( Video 1).

EUS confirmed a lesion $6.5 \mathrm{~cm}$ in diameter in the pancreatic body and tail (> Fig. 2). The optimal insertion region was determined with the guidance of the system. A targeted puncture was performed in the malignant area based on diagnosis via artificial intelligence (Al) (\Fig.3). Adequate tissue specimens were acquired after one pass with a $22 \mathrm{G}$ needle. The cytological examination found tumor cells ( $\triangleright$ Fig. 4).

No adverse event and complications were observed during or after the procedure. The patient underwent surgery, and postoperative pathology suggested
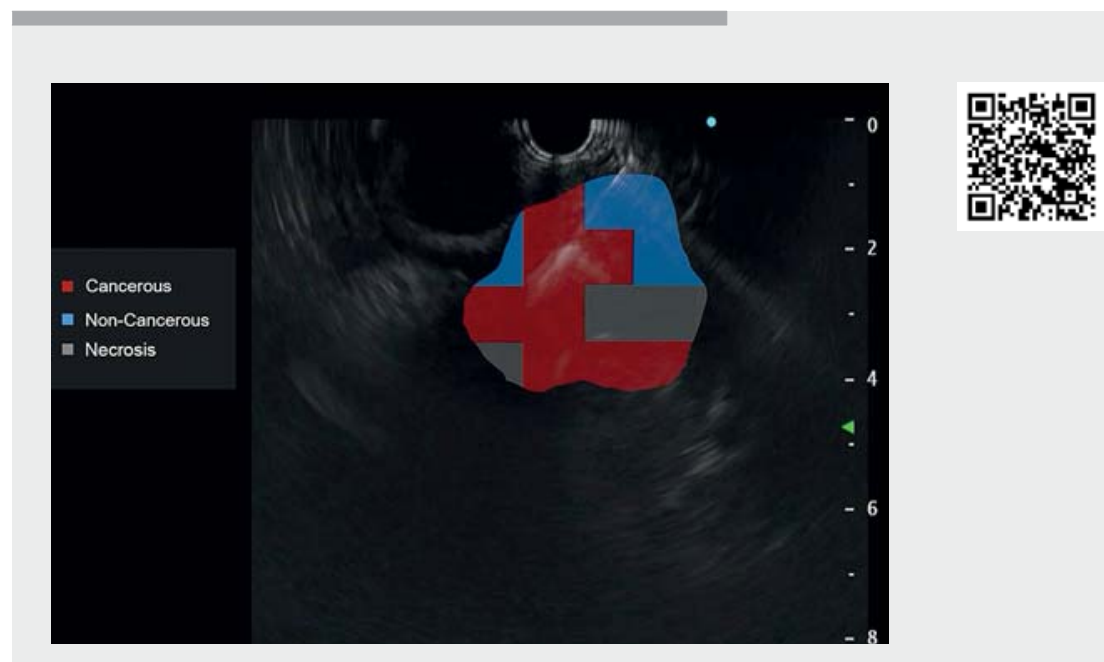

$\checkmark$ Video 1 Application of a novel artificial intelligence system in targeted puncture of a pancreatic mass. Red areas represent the malignancy where puncture was made, the blue areas are inflammation, and the gray areas are necrosis.

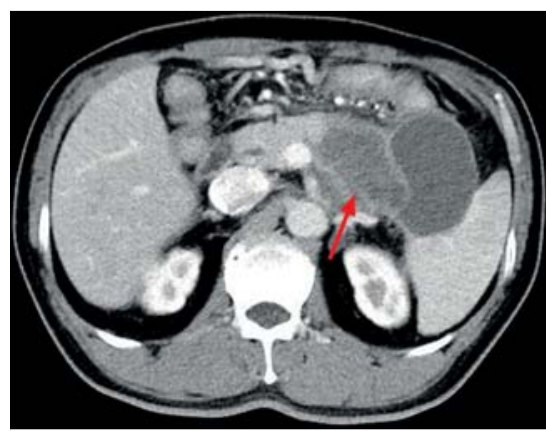

Fig. 1 Computed tomography showed a space-occupying lesion in the pancreatic body and tail.

pancreatic adenocarcinoma. Chemotherapy was then confirmed. The novel Al system is a valuable option for improving the diagnostic accuracy of EUS-FNA that can distinguish the malignant, benign, and necrotic regions in a lesion and guide the puncture.

Endoscopy_UCTN_Code_TTT_1AS_2AD

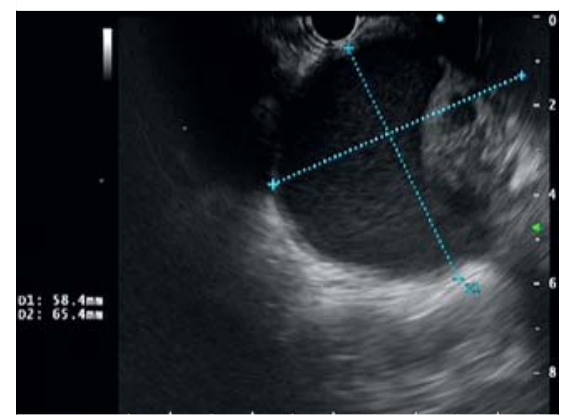

Fig. 2 Endoscopic ultrasound confirmed a lesion $6.5 \mathrm{~cm}$ in diameter in the pancreatic body and tail.

Acknowledgement

We thank Jinzhu Liu, Wujun Wang and Long Zeng from Wuhan EndoAngel Medical Technology Co., Ltd. to build the Al system.

Funding

the Hunan Provincial Science\&Technology Department of China 2020SK2013 

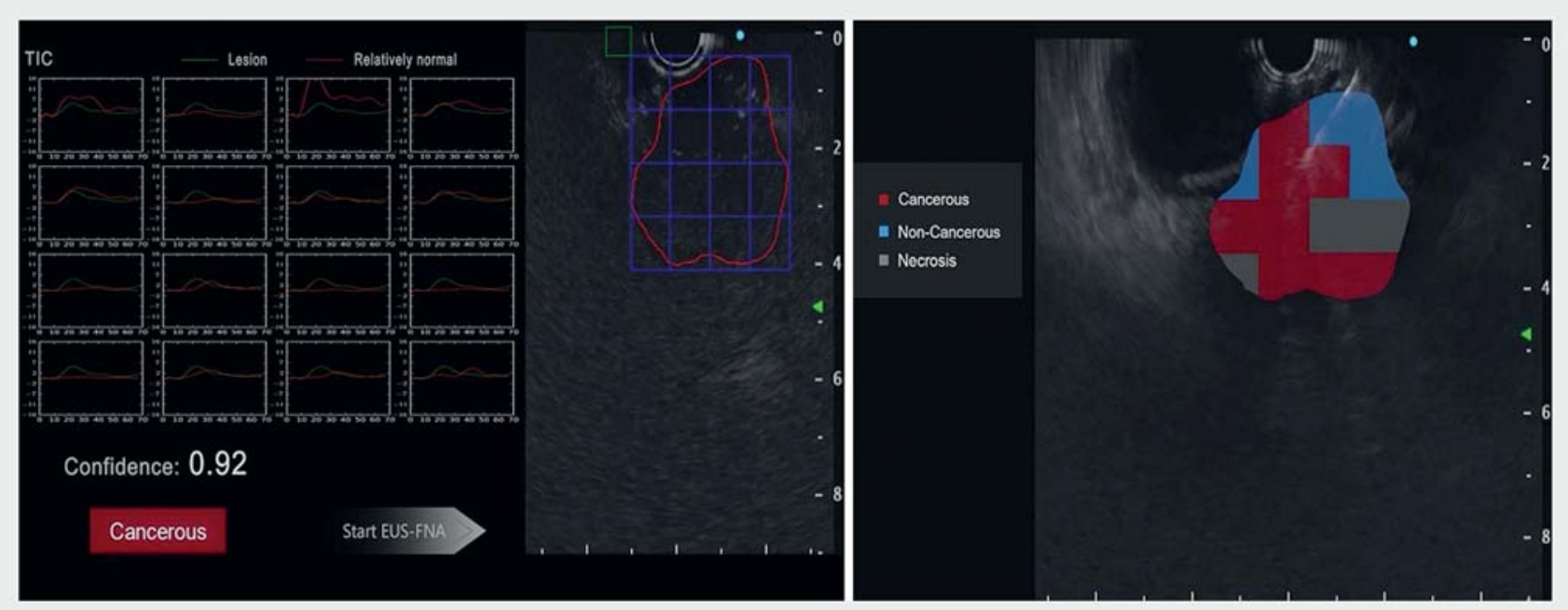

Fig. 3 The optimal insertion region was determined with guidance from the system.

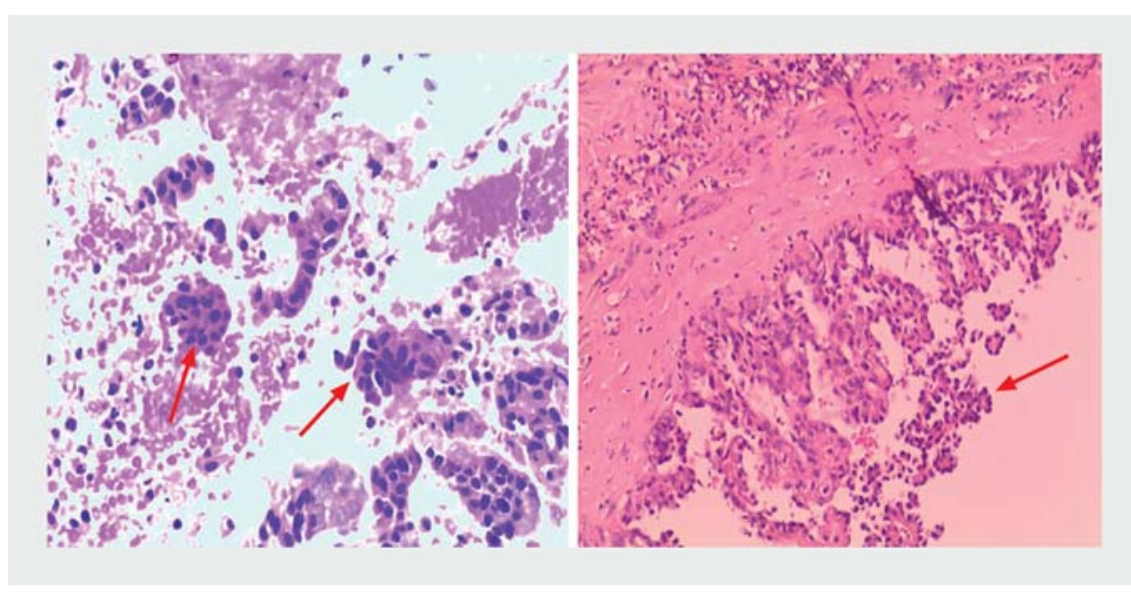

Fig. 4 The pathological examination found tumor cells and confirmed an adenocarcinoma of the pancreas.

\section{Competing interests}

The authors declare that they have no conflict of interest.

The authors

Xiaoyu Yu' ${ }^{1}$, Zinan Zhang ${ }^{1}$, Ningxin Zhu' ${ }^{1}$, Anliu Tang1, Shan $\mathrm{Hu}^{2}$, Xiaoyan Wang1 ${ }^{*}$, Li Tian ${ }^{1 *} \odot$

1 Department of Gastroenterology, The Third Xiangya Hospital of Central South University, Hunan, China

2 Wuhan EndoAngel Medical Technology Company, Wuhan, China

\section{Corresponding author}

\section{Li Tian, MD}

Department of Gastroenterology, The Third Xiangya Hospital of Central South University, 138 Tongzipo Road, Yuelu District, Changsha, Hunan, China, 410013 f3tianli@outlook.com

\section{References}

[1] Facciorusso A, Del Prete V, Buccino V et al. Diagnostic yield of Franseen and Fork-Tip biopsy needles for endoscopic ultrasoundguided tissue acquisition: a meta-analysis. Endosc Int Open 2019; 7: E1221-E1230. doi:10.1055/a-0982-2997
[2] Kamata K, Takenaka M, Omoto S et al. Impact of avascular areas, as measured by contrast-enhanced harmonic EUS, on the accuracy of FNA for pancreatic adenocarcinoma. Gastrointest Endosc 2018; 87: 158163. doi:10.1016/j.gie.2017.05.052

\section{Bibliography}

Endoscopy 2022; 54: E500-E501

DOI 10.1055/a-1625-3396

ISSN 0013-726X

published online 8.10.2021

(c) 2021. Thieme. All rights reserved.

Georg Thieme Verlag KG, Rüdigerstraße 14, 70469 Stuttgart, Germany

\section{ENDOSCOPY E-VIDEOS}

https:/|eref.thieme.de/e-videos

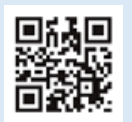

Endoscopy E-Videos is an open access online section, reporting on interesting cases and new techniques in gastroenterological endoscopy. All papers include a high quality video and all contributions are freely accessible online. Processing charges apply (currently EUR 375), discounts and wavers acc. to HINARI are available.

This section has its own submission website at

https://mc.manuscriptcentral.com/e-videos

\footnotetext{
* These authors contributed equally.
} 